\title{
The Effect of Education and Experience on Wages: The Case Study of Saudi Arabia
}

\author{
Hemaid Alsulami \\ Faculty of Engineering, King Abdulaziz University, Jeddah, KSA \\ Email: healsulami@kau.edu.sa
}

How to cite this paper: Alsulami, $H$. (2018) The Effect of Education and Experience on Wages: The Case Study of Saudi Arabia. American Journal of Industrial and Business Management, 8, 129-142. https://doi.org/10.4236/ajibm.2018.81008

Received: December 29, 2017

Accepted: January 19, 2018

Published: January 22, 2018

Copyright $\odot 2018$ by author and Scientific Research Publishing Inc. This work is licensed under the Creative Commons Attribution International License (CC BY 4.0).

http://creativecommons.org/licenses/by/4.0/

(c) (i) Open Access

\begin{abstract}
Investment in human capital is a major factor for the economic growth of the country. Working salaries are main living aims for each individual, and no one is interesting less than having a continuous increasing in the monthly income of his own. In Saudi Arabia, a variation in the individual income is a noticeable issue to be considered, and this research is looking closely at several scenarios that were conducted from the effect of several factors; education major, educational degree, experience and working sector. After these scenarios are specified, prioritization matrix technique is used to find the scenario that results in the highest income for the Saudi males and females' monthly income separately. As a result, a male who has doctoral degree in science major and has been working in a private sector from 10 to 14 years or more than 20 years is the highest monthly income among males in Saudi Arabia. While a female who has doctoral degree in science major and has been working in a public sector from 15 to 20 years or more earns the highest income among females. The results show also the most two factors that significantly affect the Saudi salaries for both males and females are education qualification and the sector either public or private.
\end{abstract}

\section{Keywords}

Education Major, Educational Degree, Experience, Working Sector, Income, Saudi Individual

\section{Introduction}

Various researches across several years have demonstrated the importance of investing in the human capital as it is one of the major factors in the economic growth for a country. Increasing the educational level and abilities of an individual are the main source of increasing productivity and economy within a so- 
ciety [1]. Education has been always one of the prominent interests inherent with the development of the modern State of Saudi Arabia. This is demonstrated by the launch of Saudi vision 2030 that includes a primary pillar in improving the educational level in Saudi Arabia by 2030. Saudi vision for 2030 stated the goal of "Education that contributes to economic growth" which supported the importance of investing in education to build a productive society [2].

There are two reasons to believe in the importance of education: first, is the great demand for education, particularly public education, in all developed and developing countries, secondly is due to the clear and strong relationship between education and income at the individual and national level [3]. Differences in incomes reflect the financial incentives for an individual to invest in further education. For instance, a graduate with a higher level of education faces a lower risk of unemployment and has greater opportunities for further training and higher income, which result in enhanced skills and higher productivity [4]. The average monthly income per Saudi individual is approximately about SR $6.5 \mathrm{k}$ according to General Authority for Statistics [5]. There are many factors playing key roles in the variation of individual's income/salary. The focus here is on studying the educational level, experience level and job sector that lead to acquire the highest Saudi individual's salary. The goal of this study is to illustrate the combination of factors that will lead to acquire the highest possible income among Saudi individuals' income. In addition, the study aims to find the highest income among Saudi males and females based on the effect of academic degree, academic major, experience and work sector.

An American study demonstrated that most of the individuals with a bachelor's degree earn an average of $\$ 2.27$ million over their lifetime, while others with master's, doctoral and professional degrees earn about $\$ 2.67$ million, $\$ 3.25$ million, and $\$ 3.65$ million, respectively. Furthermore, the study illustrated that an individual with a bachelor's degree in majors like engineering, management, and science or technology earn more than others with literature majors like community service [6]. Similarly, the Ministry of Education in New Zealand stated that the income for those with a higher education degree is higher by $24 \%$ on average, compared to those with a non-higher education degree [7]. Consequently, this can clarify the mutual relationship between the educational level and the income of an individual. Unfortunately, no data or statistics were available that show which factors affected the Saudi individual incomes with regard of the educational level, experience and work sectors. Thus, one of the purposes of this research is to survey and record the required data of the Saudi community and share the analyzed information accordingly.

\section{Literature Review}

This literature review will focus on education as a major factor affecting income at several locations. For instance, education plays an important role in a variety of domains, including economic growth, wages, income inequality and society. 


\section{The Effect of Education Level on Economic Growth}

Based on the existing literature, there is a significant evidence of the relationship between the human capital and the economic growth. While a few experimental studies focus on the impact of education levels on economic growth. Two different studies will be presented below about the impact of the educational levels on the economic growth.

Denise Hawkes and Mehmet Ugur from the University of Greenwich in London, England conducted a research in 2012 to find empirical evidence for the impact of education and skills development on economic growth in low-income countries (LICs). Hawkes and Ugur found that there is a stable positive relation between the education and skills development and the economic growth in LICs. They conducted their study using a Meta-analysis after identified and synthesis thirty-three different experimental papers. The selection of papers had a limited effect of bias due to the selection process that used PIOS framework (Population, Independent variable, Outcome, Study design) to eliminate 3842 unique studies to 33 empirical papers and 6 theoretical papers. In addition, they conducted the Meta-analysis using STATA software to avoid any errors or failures. The wide range of education and skills measures provided a limited number of observations for each type of education and this was the largest problem faced by Hawkes and Ugur. Conforming to the two researchers from the University of Greenwich, the limited number of observation may affect the importance of the results that indicated to prove the impact of education on promoting the economic growth in LICs [8].

Likewise, Gangadhar Dahal from the University of Warsaw in Poland studied the instrumental role of education between 1995 to 2013 on reducing the poverty, protecting the environment, improving the sustainability and the most important aspect is the role of education in enhancing the productivity and economic growth in developing countries such as Nepal. According to Dehal, Nepal suffers from low-skilled human resources due to poor education quality and lack of professional training and thus became a major constraint for Nepal's economic development. The objectives behind Dehal's research are to find the impact of primary, secondary and tertiary/high education on Nepal's economic growth, also to check if there is a long relationship between the education and the economic expansion. Ordinary Least Square (OLS) diagnostic and Johansson cointegration techniques are what Dehal used to achieve the aims of his study. The results of OLS diagnostic indicate that there is a significant impact of primary, secondary and tertiary education on the economic evolution in Nepal. While the results of Johansson cointegration test prove a long relationship and high contribution between the education levels and the economic growth of developing countries like Nepal. Finally, the researcher recommended the government of developing countries to invest in education and give it the top priority and time since education is playing a crucial role in the development of their economy [9]. 
The previous two papers were focusing on the role of education in economic growth. Both papers proved this result using different methods and techniques at different locations.

\section{The Effect of Education and Experience on Wages}

Through years, many research proved that work experience has a significant role on the worker wages. This part of the literature review will illustrate two papers discussed the impact of education and experience improvements on the wages increase.

Thailand as an emerging country has faced a significant gap between the rising level of educational attainment and the growing demand for skilled labor along with the dramatic difference between the urban and rural labor markets. This has been resulting in an income inequality when the wage distribution lacks uniformity across the region. Wannakairoj from the University of Washington, examine and evaluate the relationship between the education and work experience on wages in urban and rural areas in Thailand, by applying an empirical model on a raw data collected by the national statistical office of Thailand from 19,099 Thai individuals in the third quarter of 2012. The empirical model developed using the ordinary least square (OLS) regression model of Mincerian wage equation [10]. More on this topic, Shahab, Sanaullah, Ubaid Ali and Muhammad Kaleem noticed the same relation between education and experience on the wages at Khyber Pakhtunkhwa, Pakistan. They used cross-sectional survey and questionnaire design, multi-stage sampling procedures and studied three hypotheses using simple multiple regression to examine the effect of education, experience and skills on the workers' wages [11]. This study was comprehensive regarding to the work components which are education, experience and skill, and studied each factor in a separate way to observe its effect.

The results obtained from the OLS regression model done by Wannakairoj demonstrated that there is a strong relationship between the education, experience and wage with the difference in the urban and rural areas. The results also illustrated a significant positive relationship between an additional year of education and wage while the coefficient of an additional year of experience was relatively small. On the other hand, Shahab and his colleagues concluded that the coefficient of education shows that one-year increase in education can increase the income by PKR. 2370.3. Moreover, a one-year increase in experience can increase earnings by PKR. 1107.91. In addition, the coefficient of education shows that if the value of skill dummy is changed from 0 to 1 it can increase earnings by PKR. 1169.27 [11].

People usually get promoted in their work through more than one year of experience, while an additional year of education can make a difference in defining the initial job position. This indicates that an additional year of education is associated with the percentage increase in wage level [10]. The research took into consideration the differences in the labor force between the urban and rural areas. In addition, t-test was conducted to support the results of the OLS regression model. However, there was some limitation in the study. According to 
Wannakairoj [10], some assumptions have been set which limited the experiment. First, the study assumed monthly wages for the labor in the rural market while this is not the case, they receive their wages seasonally. Second, the experiment didn't consider the quality of the education although it is an important factor. Wannakairoj illustrated that the wage gap will narrow in Thailand and the income inequity will be reduced when the modern sector starts absorbing labors from the rural market. Also, the writer suggested for further studies to be conducted regarding this topic especially in Thailand and further factors should be taken into consideration.

From the previously discussed papers, the impact of education and experience has been clear by two different studies conducted at a different location by several methods.

\section{Education and Income Inequality}

At many nations, individuals suffer from income inequality as an issue specifies their life's path. For instance, researchers studied this problem and tried their best to detect the factors causing this problem and discover solutions to reduce the impact of these factors. This part will illustrate several researches which studied the role of education in income inequality problem.

For decades, the United States individuals suffered from income inequality as Scott and Jessica mentioned in their article [12]. As these two examine several types of secondary data sources (e.g. previous statistics and research), they aimed to list the factors that affect the income and cause inequality among American individuals. Pranob Kumar Mishra noticed the same issue at Maharashtra state in India. The workers at the unorganized sectors are facing high-income inequality and most of them are low paid. Pranob chose the education level as a factor to explain the inequality. Gathering primary data by conducting questioners through personal interviews and filed surveys in the labor market at Maharashtra state is the method Pranob used to conduct his study and he used SPSS, Excel and statistical graphs to analyze the findings [13]. In addition to that, Kevin Sylwester from Southern Minois University at the United States conducted a research to determine which factor will have the most significant effect in reducing the income inequality. Kevin focused in his study on two factors, increasing investments in public education and increasing human capital of the country using Gini coefficient, which was found in a previous study [14].

The results from Scott and Jessica's study demonstrated a strong relationship between education and individual's income. In fact, people with high education level are more skilled and has less chance of being unemployed. Also, the more educated the person is the more he knows how to manage his income, save money, increase wealth and reduce the chance of having debt or loans. In fact, having a strong relation between education and income does not mean that education is the only factor affecting income inequality. For instance, natural ability of the individual, assertive mating, inheritance and health are all main factors that play important role in income inequality [12]. The findings of Pranob are supporting Scott and Jessica's in considering education as a main factor 
of income inequality. For instance, he found that higher educated workers have a higher chance of getting long period contracts (e.g. Months, years) and though higher income. Also, lower educated workers do not have the ability to make future investments since they are low paid, does not have social security and work in conditions that are hazardous or unhealthy. In fact, these low educated workers are not aware of the minimum wage act, and they are paid less than the minimum without their knowledge [13]. The result of Kevin's study is to determine if expenditures in public education are more beneficial than increasing human capital of the country showed that increasing public education expenditures is more effective than increasing human capital in reducing income inequality. Kevin recommended governments to invest more in education as one factor to overcome the inequality problem. One issue in Kevin's study is that it did not consist which level of the public education (primary, secondary or high education) will be more effective to increase its expenditures [14].

The previous part discussed the education as the main factor causing income inequality. The studies persuaded increasing the level of education as one factor to reduce income inequality in societies.

\section{The Benefits of Higher Education for Individuals and Society}

Figures can illustrate the importance of education easier than words. This is what Sandy and Kathleen adopted in their report. They presented detailed evidence and pointed well-integrated picture of both the private and public benefits of higher education by integrating government statistics with some academic research from the American society. Sandy and Kathleen examined the benefits of investing in higher education to individuals and society [15]. All statistics demonstrated a correlation between the higher level of education and higher income for both men and women. Moreover, a student in the higher education obtains a variety of personal and financial benefits. Looking to the societal benefits of investing in higher education, people with high level of education faces a lower risk of unemployment and they are less likely to depend on social safety-net programs. In addition, high level of education associated with great levels of civic participation such as volunteer work and blood donation, along with the low smoking rates among colleges graduates which in return indicate to positive perceptions of personal health. The final answer is that education does pay both individuals and society benefits from the investments in higher education [15].

The Impact Grades on Salary

After discussing the importance of education in many aspects, one factor is believed to have a significant impact on salary, success and job performance and is related to education, which is the obtained grades. Philip, Roth, Richard and Clarke from Clemson University conducted a Meta-analysis to discover the relation between grades and salary as the dependent variable. They used the Hunter-Schmidt approach to analyzing the data. The reliability of grades was examined and estimated by Reilly and Warech (1993), as their correction was used in this study analysis. Based on cumulating statistics describing the correlation between grades and salary, two relations were found, a relation between grades 
with starting salary and another between grades with current salary. The Modest correlation was found with the starting salary and moderate range correlation with the current salary. The size of the grade-salary growth correlation was negligible. By these results, it was concluding and suggested that grades "may be" a meaningful predictor of current salary and a "somewhat" meaningful predictor of a starting salary. This paper tried to correct some previews studies with some correction criteria but it was depending on some previews literatures that have small sample size [16].

To sum up, this literature review illustrated the importance and impact of various levels of education on individual's income at different nations. For instance, education has a strong relationship with the countries' economic growth, since higher educated individuals are paid higher wages and countries who expenses on education will have more skilled individuals and this will reduce income inequality among them. In fact, statistics demonstrated a correlation between the higher level of education and higher benefits for both individuals and society regardless the obtained grades of education.

\section{Methodology}

The most suitable method that will simplify the process in achieving the research objectives is the prioritization matrix. Prioritization matrix is a useful technique to rank different topics generated using weighted criteria that are important to the research. It is helpful in making a priority of the available choices and provides sort diverse set of items into an order of importance [17]. The following points represent the typically used weights:

- Equally important and its weight equal to 1;

- Significantly more important and its weight equal to 5 ;

- Extremely more important and its weight equal to 10;

- Significantly less important and its weight equal to $1 / 5$;

- Extremely less important and its weight equal to $1 / 10$.

The decisions of importance will be decided based on the salary average for each factor. The studied factors with their categories will be listed in the following points:

- Academic degree:

- Doctoral Degree;

- Master Degree;

- Bachelor Degree;

- Diploma;

- High School or less.

- Education major:

- Science;

- Literature.

- Job sector;

- Public;

- Private; 
- Other.

- Experience years:

- More than 20 years;

- 15 - 20 years;

- 10 - 14 years;

- 5 - 9 years;

- Less than 5 years.

The process of constructing the prioritization matrix involves four steps [18]:

1) Define factors and their categories that represent the area of study;

2) Create the matrix for each factor by listing its categories along on columns and rows;

3) Compare between every two categories using the weights;

4) Prioritize the categories based on their total scores.

\section{Data collection}

The used method of choosing the sample is stratified random sampling, where random Saudi individuals are chosen then they are sub-grouped by their gender. The method used for data collection was a survey. The survey included eight multiple choice questions as listed in the bellow with their explanation:

1) What is your gender?

2) What is your nationality?

3) What is your living region?

4) What is your academic degree?

5) What is your educational major?

6) What is your job sector?

7) How many years of experience do you have?

8) What is your monthly salary?
Multiple choice question with two choices: Male or Female.

Multiple choice question with two choices: Saudi or non-Saudi.

Multiple choice question with two choices: Large region (including Riyadh-Makkah-Eastern Region-Madinah-Asir) or small region (AlQassim-Tabuk-Hail-Jazan-Najran-AlBahahAlJawf-Northern Borders).

Multiple choice question with five choices: High School or less, Diploma, Bachelor Degree, Master Degree or Doctoral Degree.

Multiple choice question with two choices: Science major or Literature.

Multiple choice question with three choices: employer at public job, employer at privet job or other (i.e. having his/her own business).

Multiple choice question with five choices: Has more than 20 years, between 15 - 20 years, 10 - 14 years, 5 - 9 years or less than 5 years of experience.

Multiple choice question with six choices: More than 28,000 SAR, between 20,000 - 28,000 SAR, between 15,000 - 19,999 SAR, between 10,000 - 14,999 SAR, 5000 - 9999 SAR or Less than 5000 SAR.

The total responses to the survey were 2470 response. The survey targeted Saudi employees with 18 years old. Therefore, 53 participant's responses were eliminated since it did not match with participants constraints. As the research is concerning of male and female employees' respondents separately, the first 
question helped in separating the two genders. The total female responses were $33 \%$ and the male responses were $67 \%$ as shown in Table 1 which indicates also the majority of participants were from the large regions of Saudi Arabia.

\section{Data analysis}

The raw data was analyzed using Prioritization matrix and the weights were given based on the salary average for each category. The study was conducted on Saudi males and females in order to determine which top three cases from each gender have the highest salary in Saudi Arabia. They are 150 cases and each case has one category from each factor. Table 2 listed the average salary for each category under each factor for males and females.

Table 1. Participants sociodemographic.

\begin{tabular}{|c|c|c|c|c|}
\hline \multirow{2}{*}{$\begin{array}{l}\text { Region } \\
\text { Gender }\end{array}$} & \multicolumn{2}{|c|}{$\begin{array}{c}\text { Small regions including } \\
\text { (AlQassim, Tabuk, Hail, Jazan, } \\
\text { Najran-AlBahah, Al Jawf } \\
\text { and Northern Borders) }\end{array}$} & \multicolumn{2}{|c|}{$\begin{array}{c}\text { Large regions including } \\
\text { (Riyadh, Makkah, Eastern } \\
\text { Region, Madinah and Asir) }\end{array}$} \\
\hline & Male & Female & Male & Female \\
\hline Participants & $22 \%$ & $10 \%$ & $45 \%$ & $23 \%$ \\
\hline
\end{tabular}

Table 2. Salary average for each category.

\begin{tabular}{|c|c|c|}
\hline \multicolumn{3}{|c|}{ Factor: Academic Degree } \\
\hline Category & Average Male Salary & Average Female Salary \\
\hline Doctoral Degree & 26,308 & 21,553 \\
\hline Master Degree & 19,765 & 13,038 \\
\hline Bachelor Degree & 12,538 & 11,511 \\
\hline Diploma & 9889 & 13,250 \\
\hline High School or less & 11,306 & 6333 \\
\hline \multicolumn{3}{|c|}{ Factor: Education Major } \\
\hline Category & Average Male Salary & Average Female Salary \\
\hline Science & 15,625 & 12,266 \\
\hline Literature & 12,854 & 11,479 \\
\hline \multicolumn{3}{|c|}{ Factor: Job Sector } \\
\hline Category & Average Male Salary & Average Female Salary \\
\hline Public sector & 14,410 & 13,611 \\
\hline Private sector & 17,155 & 8924 \\
\hline Other & 10,676 & 6095 \\
\hline \multicolumn{3}{|c|}{ Factor: Experience } \\
\hline Category & Average Male Salary & Average Female Salary \\
\hline Less than 5 years & 11,267 & 6568 \\
\hline $5-9$ years & 13,278 & 10,260 \\
\hline $10-14$ years & 16,250 & 10,216 \\
\hline 15 - 20 years & 14,846 & 13,095 \\
\hline More than 20 years & 18,382 & 15,452 \\
\hline
\end{tabular}


The following tables (Tables 3-10) will illustrate the Prioritization matrix for each factor and the weights was assigned to each category based on the comparison of the categories' monthly average salary. Tables 3-6 belong to males' data while Tables 7-10 belong to females' data.

Based on the conducted matrices the categories' priority percent under each factor are as the following:

Table 3. Prioritization matrix of academic degree factor for males.

\begin{tabular}{|c|c|c|c|c|c|c|c|}
\hline $\begin{array}{l}\text { Academic } \\
\text { Degree }\end{array}$ & Doctoral & Master & Bachelor & Diploma & $\begin{array}{l}\text { High School } \\
\text { or less }\end{array}$ & $\begin{array}{l}\text { Row } \\
\text { Total }\end{array}$ & $\begin{array}{c}\text { Decimal } \\
\text { Value }\end{array}$ \\
\hline Doctoral & & 5.00 & 10.00 & 10.00 & 10.00 & 35.00 & 0.51 \\
\hline Master & 0.20 & & 5.00 & 10.00 & 5.00 & 20.20 & 0.30 \\
\hline Bachelor & 0.10 & 0.20 & & 5.00 & 1.00 & 6.30 & 0.09 \\
\hline Diploma & 0.10 & 0.10 & 0.20 & & 0.20 & 0.60 & 0.01 \\
\hline \multirow[t]{2}{*}{ High School or less } & 0.10 & 0.20 & 1.00 & 5.00 & & 6.30 & 0.09 \\
\hline & & & & & Total & 68.40 & \\
\hline
\end{tabular}

Table 4. Prioritization matrix of education major factor for males.

\begin{tabular}{|c|c|c|c|c|}
\hline Education Major & Science & Literature & Row Total & Decimal Value \\
\hline Science & & 5.00 & 5.00 & 0.96 \\
\hline \multirow[t]{2}{*}{ Literature } & 0.20 & & 0.20 & 0.04 \\
\hline & & Total & 5.20 & \\
\hline
\end{tabular}

Table 5. Prioritization matrix of job sector factor for males.

\begin{tabular}{cccccc}
\hline Job Sector & Public & Private & Other & Row Total & Decimal Value \\
\hline Public & & 0.20 & 5.00 & 5.20 & 0.25 \\
Private & 5.00 & & 10.00 & 15.00 & 0.73 \\
Other & 0.20 & 0.10 & & 0.30 & 0.01 \\
& & & Total & 20.50 & \\
\hline
\end{tabular}

Table 6. Prioritization matrix of years of experience factor for males.

\begin{tabular}{cccccccc}
\hline Experience/Years & $<5$ & $5-9$ & $10-14$ & $15-20$ & $>20$ & Row Total & Decimal Value \\
\hline$<5$ & & 0.20 & 0.10 & 0.20 & 0.10 & 0.60 & 0.01 \\
$5-9$ & 5.00 & & 0.20 & 1.00 & 0.20 & 6.40 & 0.12 \\
$10-14$ & 10.00 & 5.00 & & 5.00 & 1.00 & 21.00 & 0.38 \\
$15-20$ & 5.00 & 1.00 & 0.20 & & 0.20 & 6.40 & 0.12 \\
$>20$ & 10.00 & 5.00 & 1.00 & 5.00 & & 21.00 & 0.38
\end{tabular}


Table 7. Prioritization matrix of academic degree factor for females.

\begin{tabular}{cccccccc}
\hline $\begin{array}{c}\text { Academic } \\
\text { Degree }\end{array}$ & Doctoral & Master & Bachelor & Diploma & $\begin{array}{c}\text { High School } \\
\text { or less }\end{array}$ & $\begin{array}{c}\text { Row } \\
\text { Total }\end{array}$ & $\begin{array}{c}\text { Decimal } \\
\text { Value }\end{array}$ \\
\hline Doctoral & & 5.00 & 5.00 & 5.00 & 10.00 & 25.00 & 0.53 \\
Master & 0.20 & & 1.00 & 1.00 & 5.00 & 7.20 & 0.15 \\
Bachelor & 0.20 & 1.00 & & 1.00 & 5.00 & 7.20 & 0.15 \\
Diploma & 0.20 & 1.00 & 1.00 & & 5.00 & 7.20 & 0.15 \\
High School or less & 0.10 & 0.20 & 0.20 & 0.20 & & 0.70 & 0.01 \\
& & & & & Total & 47.30 & \\
\hline
\end{tabular}

Table 8. Prioritization matrix of education major factor for females.

\begin{tabular}{ccccc}
\hline Education Major & Science & Literature & Row Total & Decimal Value \\
\hline Science & & 5.00 & 5.00 & 0.96 \\
Literature & 0.20 & & 0.20 & 0.04 \\
& & Total & 5.20 & \\
\hline
\end{tabular}

Table 9. Prioritization matrix of job sector factor for females.

\begin{tabular}{cccccc}
\hline Job Sector & Public & Private & Other & Row Total & Decimal Value \\
\hline Public & & 5.00 & 5.00 & 10.00 & 0.81 \\
Private & 0.20 & & 1.00 & 1.20 & 0.10 \\
Other & 0.20 & \multirow{2}{*}{1.00} & & 1.20 & 0.10 \\
& & & Total & 12.40 & \\
\hline
\end{tabular}

Table 10. Prioritization matrix of years of experience factor for females.

\begin{tabular}{cccccccc}
\hline Experience/Years & $<5$ & $5-9$ & $10-14$ & $15-20$ & $>20$ & Row Total & Decimal Value \\
\hline$<5$ & & 0.20 & 0.20 & 0.10 & 0.10 & 0.60 & 0.01 \\
$5-9$ & 5.00 & & 1.00 & 0.20 & 0.20 & 6.40 & 0.12 \\
$10-14$ & 5.00 & 1.00 & & 0.20 & 0.20 & 6.40 & 0.12 \\
$15-20$ & 10.00 & 5.00 & 5.00 & & 1.00 & 21.00 & 0.38 \\
$>20$ & 10.00 & 5.00 & 5.00 & 1.00 & & 21.00 & 0.38 \\
& & & & & Total: & 55.40 & \\
\hline
\end{tabular}

- Academic degree:

- Doctoral Degree with $51 \%$ priority for males and $53 \%$ priority for females;

- Master Degree with 30\% priority for males and 15\% priority for females;

- Bachelor Degree with 9\% priority for males and 15\% priority for females;

- Diploma with $1 \%$ priority for males and $15 \%$ priority for females;

- High School or less with $9 \%$ priority for males and $1 \%$ priority for females. 
- Education major:

- Science with $96 \%$ priority for males and females;

- Literature with $4 \%$ priority for males and females.

- Job sector:

- Public with 25\% priority for males and $81 \%$ priority for females;

- Private with $73 \%$ priority for males and $10 \%$ priority for females;

- Other with $1 \%$ priority for males and $10 \%$ priority for females.

- Experience years:

- More than 20 years with 38\% priority for males and females;

- 15 - 20 years with $12 \%$ priority and $38 \%$ priority for females;

- 10 - 14 years with $38 \%$ priority and $12 \%$ priority for females;

- 5 - 9 years with $12 \%$ priority for males and females;

- Less than 5 years with $1 \%$ priority for males and females.

After that, the score for each case has been calculated by multiplying the priority percentages of the categories. The following tables (Table 11 and Table 12) illustrate the cases with the highest weight for males and females respectively.

According to Table 10, the Saudi males who have the highest income are:

Table 11. Cases weights for males.

\begin{tabular}{cc}
\hline Cases & Score $\%($ Male $)$ \\
\hline Doctoral_Science_Public_10 - 14 & $4.73 \%$ \\
Doctoral_Science_Public_>20 & $4.73 \%$ \\
Doctoral_Science_Private_5 - 9 & $4.16 \%$ \\
Doctoral_Science_Private_10 - 14 & $13.65 \%$ \\
Doctoral_Science_Private_15 - 20 & $4.16 \%$ \\
Doctoral_Science_Private_>20 & $13.65 \%$ \\
Master_Science_Private_10 - 14 & $7.88 \%$ \\
Master_Science_Private_>20 & $7.88 \%$ \\
\hline
\end{tabular}

Table 12. Cases weights for females.

\begin{tabular}{cc}
\hline Cases & Score $\%$ (Female) \\
\hline Doctoral_Science_Public_5 - 9 & $4.73 \%$ \\
Doctoral_Science_Public_10 - 14 & $4.73 \%$ \\
Doctoral_Science_Public_15 - 20 & $15.54 \%$ \\
Doctoral_Science_Public_>20 & $15.54 \%$ \\
Master_Science_Public_15 - 20 & $4.47 \%$ \\
Master_Science_Public_>20 & $4.47 \%$ \\
Bachelor_Science_Public_>20 & $4.47 \%$ \\
Diploma_Science_Public_15 - 20 & $4.47 \%$ \\
Diploma_Science_Public_>20 & $4.47 \%$
\end{tabular}


1) A male who has doctoral degree in science major and has been working in a private sector from 10 to 14 years or more than 20 years.

2) A male who has master degree in science major and has been working in a private sector from 10 to 14 years or more than 20 years.

3) A male who has doctoral degree in science major and has been working in a public sector from 10 to 14 years or more than 20 years.

The Saudi females who have the highest income are:

1) A female who has doctoral degree in science major and has been working in a public sector from 15 to 20 years or more.

2) A female who has doctoral degree in science major and has been working in a public sector from 5 to 14 years.

3) A female who has master degree in science major and has been working in a public sector from 15 to 20 years or more. Also, a female who has bachelor in science major and has been working in a public sector for more than 20 years. Finally, a female who has diploma degree in science major and has been working in a public sector from 15 to 20 years or more.

Therefore, the results show that the most two factors that significantly affect the Saudi Salaries for both male and male is education qualification and the sector either public or private sector. Hence, Saudis who want to increase their income should carefully look at these two factors and do extra work to improve education qualification or may shift from public to private sector.

\section{Conclusion and Recommendation}

In an attempt to research about the explanation of the differences in people income around the world, one interesting issue is what can cause this variation in the individual income. Saudi individual both males or females who might be of the same age and work in the same field can gain different amounts of monthly salary due to different factors that can cause this variation. This paper looked closely at several scenarios regarding the factors that caused the variation in the salary of Saudi individuals and specified which factors resulted in the highest salary. As a future recommendation, this research can be made in more specific details according to specifying several factors, study each factor and find if they have significant impact on the individual salary using statistical analysis. Moreover, it is recommended to increase the number of sample size, also, study different factors, and find which factor is highly increasing the individual salary either for male or female. Furthermore, in Saudi Arabia, there are several regions such as the western, eastern and middle region which can be studied separately, and compare between them to find out if factors that cause the salary to increase, differ from region to another.

\section{Acknowledgements}

The author would like to acknowledge the contributions made by the following individuals: Dania Al-Fozan, Heba Gogandy Khadija Mughrbil and Roaa Felimban. They have provided valuable inputs while being students at the Industrial 
Engineering Seminar Course.

\section{References}

[1] Sadeghi, J.M., Shirouyehzad, L. and Samadi, S. (2012) Estimating the Impact of Education on Income with Econometric Approach: A Case Study in Universities. International Journal of Academic Research in Business and Social Sciences, 2, 175 185.

[2] Education in Saudi Vision 2030, Saudi Vision 2030. http://vision2030.gov.sa/en

[3] Almaliki, A.B.M. and Obeid, B. (2010) Ahmad Ben Suleiman. 2010. Economic Growth and Education in Saudi Arabia: An Application of Simultaneous Equations Method, Alriyad, Saudi Arabia Kingdom.

[4] Ball, R., Robin, A. and Wu, J.S. (2003) Incentives versus Standards: Properties of Accounting Income in Four East Asian Countries. Journal of Accounting and Economics, 36, 235-270.

[5] Household Expenditure and Income Survey, General Authority for Statistics. https://www.stats.gov.sa/en/37

[6] Burnsed, B. (2011) How Higher Education Affects Lifetime Salary, U.S. News \& World Report.

https://www.usnews.com/education/best-colleges/articles/2011/08/05/how-higher-e ducation-affects-lifetime-salary

[7] Impact of Education on Income, Education Counts. http://www.educationcounts.govt.nz/statistics/indicators/main/education-and-learn ing-outcomes/impact_of_education_on_income

[8] Hawkes, U. (2012) Evidence on the Relationship between Education, Skills and Economic Growth in Low-Income Countries. The EPPI Centre, London.

[9] Nowak, G.D.A.Z. (2016) The Contribution of Education to Economic Growth: Evidence from Nepal.

[10] Wannakrairoj, W. (2013) The Effect of Education and Experience on Wages: The Case Study of Thailand in 2012. Southeast Asian Journal of Economics, 1, 27-48.

[11] e Saqib, S., Panezai, S., Ali, U. and Kaleem, M. (2016) The Effects of Education, Experience and Skill on Individuals' Earning: Empirical Evidence from Khyber Pakhtunkhwa, Pakistan. International Journal of Advanced and Multidisciplinary Social Science, 2, 27-32.

[12] Scott, J.S. and Wolla, A. Education, Income, and Wealth. Page One Economics, 7. https://files.stlouisfed.org/files/htdocs/publications/page1-econ/2017-01-03/educati on-income-and-wealth_TE.pdf

[13] Mishra, P.K. (2015) Sustainability Impact of Education on Economic Behaviour Pattern of Unorganized Labourers, 18.

[14] Sylwester, K. (2002) Can Education Expenditures Reduce Income Inequality? Economics of Education Review, 21, 43-52.

[15] Baum, S. and Payea, K. (2004) The Benefits of Higher Education Foor Individuals and Society. Education Pays.

[16] Philip, L. (1998) Meta-Analyzing the Relation between Grades and Salary. Journal of Vocational Behavior, 53, 386-400.

[17] Gosenheimer, C. (2012) Office of Quality Improvement. Project Prioritization, 2-3.

[18] The Total Population in 2016, General Authority for Statistics in Kingdom of Saudi Arabia, 2017.

https://www.stats.gov.sa/sites/default/files/en-demographic-research-2016_4.pdf 